\title{
Friction Stir Welding of Dissimilar Aluminum Alloys
}

\author{
Hassan Abd El-Hafez, Abla El-Megharbel ${ }^{*}$ \\ Department of Production Engineering and Mechanical Design, Faculty of Engineering, \\ Port Said University, Port Said, Egypt \\ Email: *aelmegharbel@eng.psu.edu.eg
}

How to cite this paper: Abd El-Hafez, H. and El-Megharbel, A. (2018) Friction Stir Welding of Dissimilar Aluminum Alloys. World Journal of Engineering and Technology, 6, 408-419.

https://doi.org/10.4236/wjet.2018.62025

Received: March 5, 2018

Accepted: May 22, 2018

Published: May 25, 2018

Copyright $\odot 2018$ by authors and Scientific Research Publishing Inc. This work is licensed under the Creative Commons Attribution International License (CC BY 4.0).

http://creativecommons.org/licenses/by/4.0/

\section{(c) (i) Open Access}

\begin{abstract}
Dissimilar aluminum alloys AA2024-T365 and AA5083-H111 were welded by friction stir process. Welding parameters such as tool rotational speed (900, 1120 and $1400 \mathrm{rpm}$ ), weld speeds (16, 40 and $80 \mathrm{~mm} / \mathrm{min}$ ) and tool pin profiles (square, triangular and stepped) were used to weld many joints to study their effect on the mechanical properties of the joint. Also, different locations of the material were studied as other parameter. The mechanical properties were evaluated using tensile and hardness tests. The microstructure characterization of the processed alloys was carried out using optical microscopy. Macro and microstructures of parent and welded specimens indicated that the weld parameters have a significant effect on mechanical and microstructural properties of the welds. However, defect-free as well as higher strength was obtained at higher speed of $80 \mathrm{~mm} / \mathrm{min}$.
\end{abstract}

\section{Keywords}

Friction Stir Welding, Dissimilar Aluminum Alloys, Welding Parameters, Metallographic, AA7075, AA5083

\section{Introduction}

Friction stir welding (FSW) is widely used for joining aluminum alloys in marine, aerospace, automotive industries, and many other applications of commercial importance. The difficulty of making high-strength, fatigue and fracture resistant welds in aerospace aluminum alloys has long inhibited the wide use of welding for joining aerospace and marine structures [1] [2].

Many researchers [3] [4] [5] [6] [7] have worked on the joining of similar metals but few works have been carried out on new advanced dissimilar metals. Dissimilar metal joining processes using FSW are arduous to achieve because the 
base metals have different heat transfer coefficients, different chemical compositions and different deformation values which cause asymmetry in both heat generation and material flow. These, in turn, could lead to a possible formation of detrimental intermetallic compounds which would burden the selection of proper welding parameters [2] [8] [9].

Kumar et al. [10] used various pin profiles to perform friction stir welding of AA6061 and AA2024 alloys. The results showed that the tensile strength of the joints conducted with squared-pin profile tool, compared to the strength obtained when tapered, as well as when cylindrical pin profile tools were used, was improved.

Dinaharan et al. [11] investigated the effect of material locations and tool rotational speed on the microstructure and tensile strength of the dissimilar friction stir welded, cast and wrought aluminum alloy AA6061. They concluded that the material placed in the advancing side (AS) occupied the major portion of the weld zone when tool rotational speed was increased, where the AS of the weld is hotter than the retreating side as proved by Cole et al. [12]. In addition, Sundaram and Murugan [13] studied the effect of the pin profile used in FSW on the mechanical properties of 2024-T6/5083-H321 dissimilar aluminum alloys where the alloy of higher strength (2024) was located at the retreating side (RS). They proved that when the combinations of parameters create either very low or very high frictional heat, a plastic flow of material, lower tensile strength and elongation is observed. Furthermore, Khodir and Shibayanagi [14] experimentally examined the FSW of dissimilar materials, namely AA2024 and AA7075 and recommended that the low-strength material should be placed on the AS to produce better welds. On the other hand, Jata et al. [15] and Xue et al. [16] confirmed that locating hard materials at the AS will improve the joint strength. Accordingly, the material flow and the joint performance, irrespective of material placement, are dependent on the welding conditions and on their effects on generated heat and stir zone (SZ) temperatures [12] [17]. Additionally, heat dissipation depends on material thickness, the welding speed and the ambient temperature [12] [18]. The use of high heat input such as low welding speed and high rotation rate can result in improper tool/material contact conditions (slipping conditions) which can produce joints with defects [19]. Otherwise, El-Sayed et al. [20] were proved, experimentally and theoretically, that tool pin profile has a minor effect on the maximum temperature of the welded joints at the same welding speed.

Based on the carried-out literature review, it is seen that there is an unsolved contradiction about the proper selection of: the welding parameters, particularly material location when conducting FSW of dissimilar materials, the tool profile and the suitable combination of welding conditions. In this context, this study is intended to investigate the effect of friction stir welding parameters on the joint soundness of dissimilar AA5083-H111/AA2024-T351 alloys aiming to identify the optimum welding parameters of such materials, which could be used for marine and aerospace industries. 


\section{Experimental Work}

Dissimilar aluminum alloys 5083-H111 and 2024-T351 were friction stir welded. The materials were received in $5 \mathrm{~mm}$ thick sheets with the required dimensions of $250 \times 100 \mathrm{~mm}$. The chemical compositions and mechanical properties of the Al-alloys are listed in Table 1 and Table 2, respectively.

Primary experiments were carried out at various welding parameters to choose the suitable parameters that produce joints without visible defects.

The FSW process were performed at chosen welding parameters such as welding speed (WS), rotational speed (RS), pin geometry and material location as listed in Table 3. In additions to the microstructure investigation using the optical microscopy and visual inspection, the joints' performance was evaluated using tensile and hardness tests. The microhardness measurements were performed at mid-thickness by Vickers hardness tester using a $0.5 \mathrm{Kg}$ load.

Heat-treated tool steel H13 was used to manufacture the welding tools with concave shoulders of $20 \mathrm{~mm}$ diameter and $5 \mathrm{~mm}$ pin diameter with $4.7 \mathrm{~mm}$ height, Figure 1.

In order to assess the joints performance, the specimens were cut perpendicular to the welding line. The tensile specimens were milled to the standard dimensions according to ASTM-E8. The metallographic and hardness specimens were ground and polished down to $3 \mathrm{~mm}$ using diamond paste. It was difficult to use one popular reagent for etching the joints of dissimilar alloys, AA5083 and AA2024, and thus, various reagents were applied to each specimen. In particular, two reagents were used in this study. The first one was Killer's reagent composed of methanol $(25 \mathrm{~mL})$, hydrochloric acid $(25 \mathrm{~mL})$, nitric acid $(25 \mathrm{~mL})$ and a drop of hydrofluoric acid. However, the second reagent was recommended in [21] where the etching process involved two steps; three minutes pre-etch with a $1 \mathrm{~g}$ solution of $\mathrm{NaCl}$ in $50 \mathrm{~mL}$ of $\mathrm{H}_{3} \mathrm{PO}_{4}(40 \%)$ at $70^{\circ} \mathrm{C}$, followed by applying Weck's reagent $\left(100 \mathrm{~mL} \mathrm{H}_{2} \mathrm{O}+1 \mathrm{~g} \mathrm{NaOH}+4 \mathrm{~g} \mathrm{KMnO}_{4}\right)$. After that, the metallographic specimens were examined using an optical microscope with image analysis software.

Table 1. The chemical composition of as received Al-alloys.

\begin{tabular}{cccccccccc}
\hline \multirow{2}{*}{ Material } & \multicolumn{8}{c}{ Chemical composition, wt\% } \\
\cline { 2 - 11 } & $\mathrm{Si}$ & $\mathrm{Fe}$ & $\mathrm{Cu}$ & $\mathrm{Mn}$ & $\mathrm{Mg}$ & $\mathrm{Cr}$ & $\mathrm{Zn}$ & $\mathrm{Ti}$ & $\mathrm{Al}$ \\
\hline $\mathrm{Al} 5083-\mathrm{H} 111$ & 0.1344 & 0.3411 & 0.0282 & 0.4380 & 4.0838 & 0.0946 & 0.0389 & 0.0072 & Bal. \\
Al 2024-T351 & 0.50 & 0.50 & 4.2 & 0.50 & 1.7 & 0.10 & 0.25 & 0.15 & Bal. \\
\hline
\end{tabular}

Table 2. The mechanical properties of as received Al-alloys.

\begin{tabular}{cccccc}
\hline $\begin{array}{c}\text { Mechanical } \\
\text { properties }\end{array}$ & $\begin{array}{c}\text { Tensile Strength } \\
(\mathrm{MPa})\end{array}$ & $\begin{array}{c}\text { Yield Strength } \\
(\mathrm{MPa})\end{array}$ & $\begin{array}{c}\text { Elongation } \\
(\%)\end{array}$ & $\begin{array}{c}\text { Vickers } \\
\text { Hardness }\end{array}$ & $\begin{array}{c}\text { Elastic } \\
\text { Modulus (GPa) }\end{array}$ \\
\hline Al 5083 H111 & 279.1 & 152 & 26 & 79 & 72 \\
$\mathrm{Al} 2024 \mathrm{~T} 351$ & 469 & 390 & 13 & 130 & 73.1 \\
\hline
\end{tabular}


Table 3. The welding parameters.

\begin{tabular}{cccc}
\hline $\begin{array}{c}\text { Material Location } \\
(\text { AS/RS })\end{array}$ & Pin Profile & Rotational speed (RS); rpm & $\begin{array}{c}\text { Welding speed (WS); } \\
\mathrm{mm} / \mathrm{min}\end{array}$ \\
\hline & & 900 & $16,40,80$ \\
$2024 / 5083$ & square & 1120 & 16 \\
& & 1400 & \\
& Prism & & \\
& stepped & 900 & \\
\hline
\end{tabular}

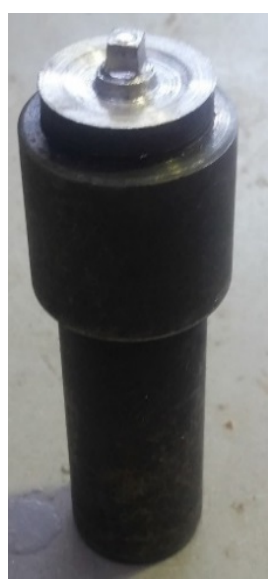

(a)

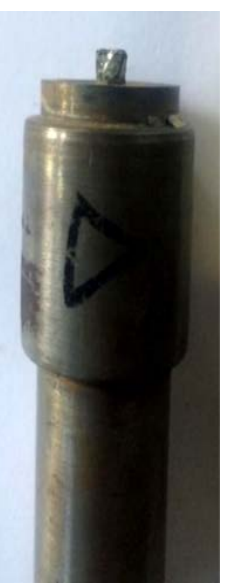

(b)

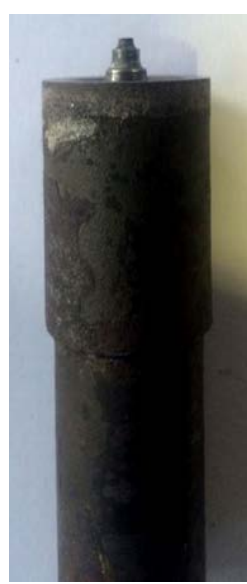

(c)

Figure 1. Photographs of the welding tools. (a) Square; (b) Triangular; (c) Stepped.

\section{Results and Discussion}

Visual inspection of the specimens revealed various defects such as tunnel and voids in the weld as shown in Figure 2. The type and size of these defects can be attributed to the lack of penetration resulted from insufficient material flow under and around the pin. This is mainly due to the low-or excess heat input which, in turn, did not permit the tool to fill the zone behind the pin. This can be concluded considering that most of the observed defects were located at the welding line and/or shifted to the AS in agreement with prior studies [22] [23]. However, the slipping of metal on the pin is considered another incentive for defects to form at the advancing zone as observed by Leitão et al. [19].

However, it is worth stating that the metal flow depends on the quantity of heat produced from friction, which is related to the RS, WS, shoulder size and the distance from the weld face. Therefore, the detected defects are located near the root, far away from the tool shoulder as proved by previous studies [22] [23] [24]. These defects have a profound effect on the joint strength which will be discussed in a further section. 


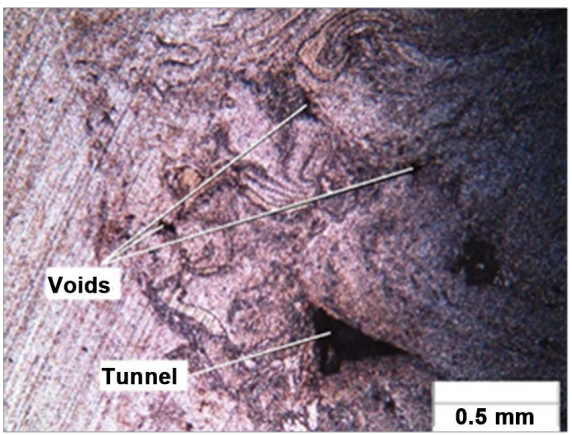

(a)

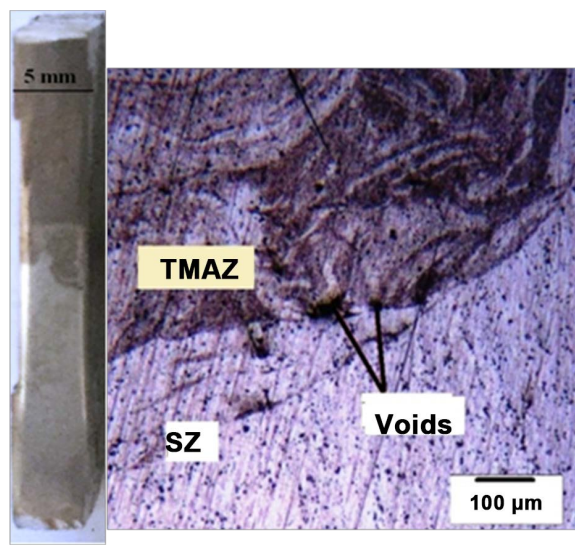

(b)

Figure 2. Photograph and micrographs for some welding defects. (a) Tunnel defect; (b) Voids.

\subsection{Microstructure Investigation}

The microstructures of the base alloys AA2024 and AA5083 are shown in Figure 3 which helping at evaluation the effect of welding parameters on the FS-joint microstructures. As an example, the microstructures of three welded specimens are shown in Figure 4 at various RS and invariable WS of $40 \mathrm{~mm} / \mathrm{min}$. The micrographs show the stir zone (SZ) and thermomechanical affected zone (TMAZ). It can be noticed that the stirring behavior as well as the mixing of dissimilar alloys varies from one specimen to another. This difference is related to the stirring efficiency and the amount of generated heat as mentioned by Akbari et al. [25] and Saravanan et al. [26]. However, it is noticed that increasing the produced heat improved the homogeneity as well as grain size in the SZ as shown in Figure 4(c).

A layer with very fine homogeneous grains was formed under the shoulder, Figure 5. This layer has varying thicknesses which differs from one specimen to another. However, the layers were found to have gradient increases of the thickness from the shoulder's center towards the shoulder's circumference. This deviation is due to the variation of the heat produced over the shoulder due to the varying linear speeds. These layers were expected to improve the performance of the joints in terms of higher hardness and strength at weld face. Accordingly, it can be noticed that the microstructure of SZ and TMAZ is affected by the welding speeds that control the produced amount of heat which is in good agreement with YOON et al. [22].

\subsection{The Hardness Behaviour}

The Vickers microhardness tests were conducted across various regions of the weld. Figure 6 shows the hardness profile across the welded alloys for some specimens that welded at constant WS of $16 \mathrm{~mm} / \mathrm{min}$ and various RS of 900, 1120 and $1400 \mathrm{rpm}$. For each specimen, it could be recognized three different regions throughout the specimen. These variations can be attributed to the difference in 


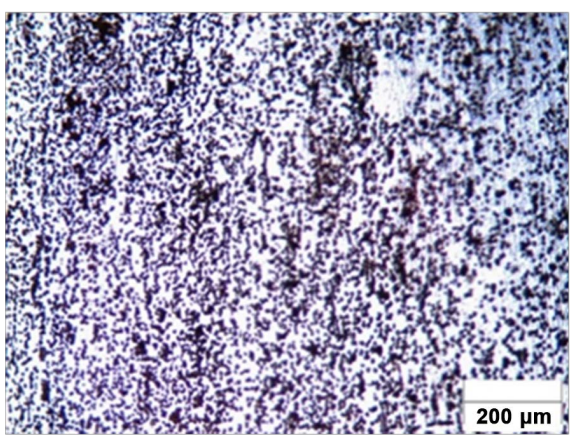

(a)

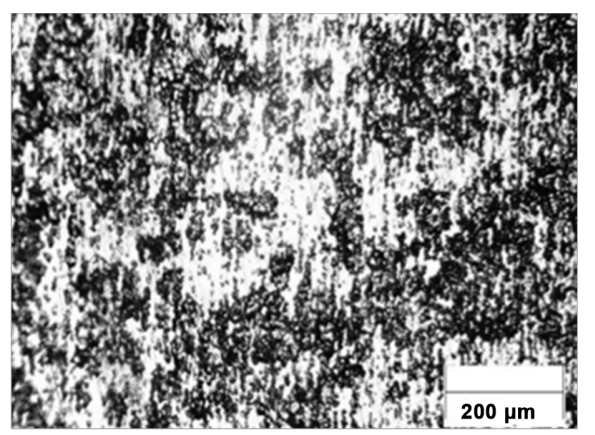

(b)

Figure 3. Microstructure of the base alloys. (a) AA2024; (b) AA5083.

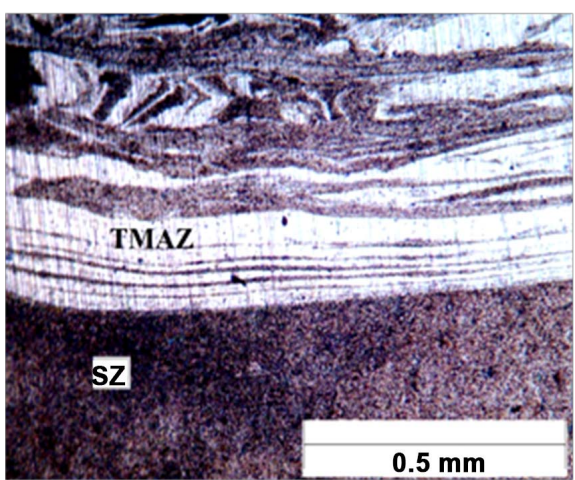

(a)

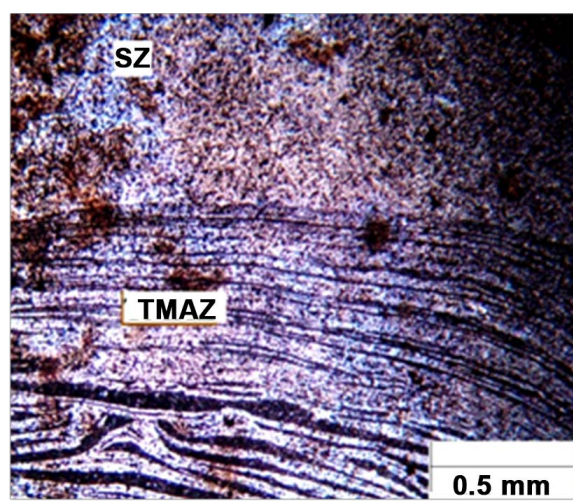

(b)

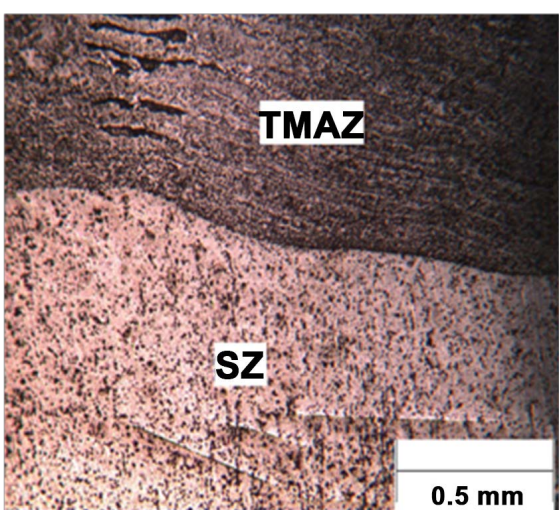

(c)

Figure 4. Microstructure of the SZ/TMAZ for some specimens using square pin. (a) 1400 $\mathrm{rpm}$; $40 \mathrm{~mm} / \mathrm{min}$; (b) $900 \mathrm{rpm} \& 40 \mathrm{~mm} / \mathrm{min}$; (c) $1400 \mathrm{rpm} \& 16 \mathrm{~mm} / \mathrm{min}$.

microstructure, the homogeneity of the phases in the SZ and the blend behavior of the base alloys [27]. In particular, the first region of AA 5083-base alloy can be clearly discerned by the negligible variation of the hardness values. However, noticeable variation of the hardness values was obtained in the second region, the so called TMAZ region. In the third region, the stirring zone, a slight reduction of the hardness values was found but with less variation.

However, the hardness behavior was nearly the same for all specimens with minor variations in value. The variation from one specimen to another can be 


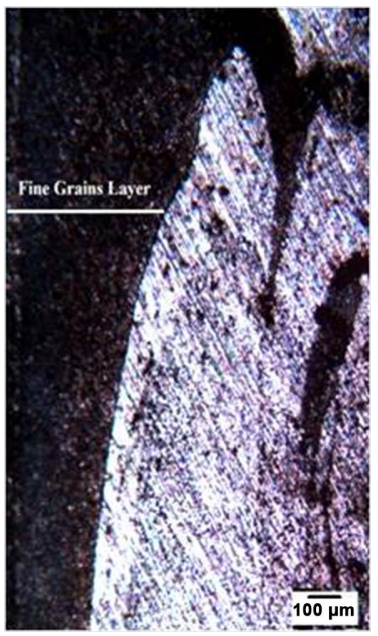

Figure 5. Microstructure shows the layer under shoulder.

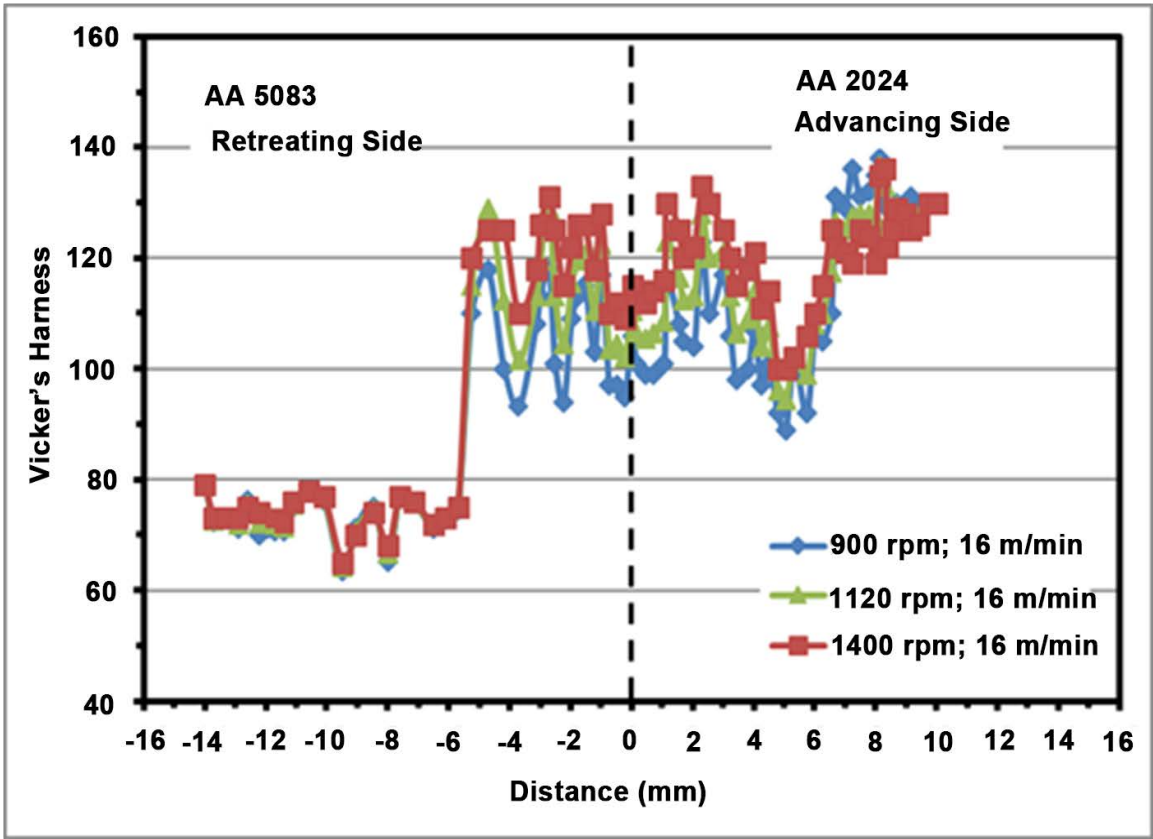

Figure 6. The hardness profile for FSW specimen.

explained by the influence of the welding parameters on matters such as grain size and mixing performance as reported by other researchers [22] [27].

\subsection{Tensile Strength}

Figure 7 shows the effect of RS on the joint's strength at various WS. At 16 $\mathrm{mm} / \mathrm{min}$, a decrease in the strength was noticed with the increase in the RS. Increasing the WS to $40 \mathrm{~mm} / \mathrm{min}$ revealed lower strength values of the joint, especially at $1120 \mathrm{rpm}$. In addition, the strength for welded joint at $40 \mathrm{~mm} / \mathrm{min}$ is lower, for all joints, than that at $80 \mathrm{~mm} / \mathrm{min}$ with nearly a $16 \%$ decrease at 900 rpm up to $47 \%$ at $1120 \mathrm{rpm}$. This can be related to the faster WS which 


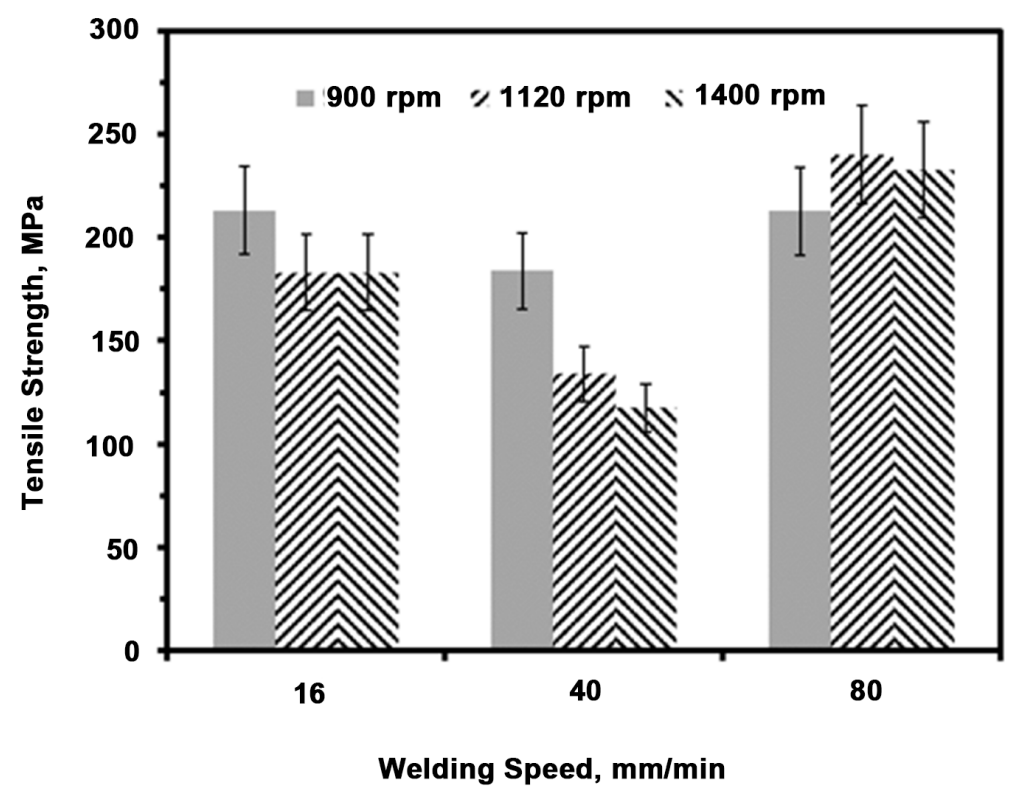

Figure 7. Effect of rotational and welding speeds on the FS-Joints.

decreases the heat amount leading to inappropriate slipping conditions as confirmed by Leitão et al. [19]. On the other hand, at $80 \mathrm{~mm} / \mathrm{min}$, the strength is increased to highest values due to the more suitable generated heat leading to efficient metal mixing and good metal flow.

However, the strength results can be correlated to the voids or micro-defects presented through the welding zones. The size and shape of defects have a significant effect on the tensile strength where all specimens were fractured at $\mathrm{SZ}$ or TMAZ started from root as shown in Figure 8. Some specimens, such as (1120 $\mathrm{rpm}, 80 \mathrm{~mm} / \mathrm{min}$ ) have no defects, achieved best strength.

Also, the effect of WS at different rotational speeds on the FS-joints strength is studied, Figure 7. It could be noticed that the WS has an insignificant effect on the joints strength at the lower rotational speed of $900 \mathrm{rpm}$. On the other hand, at $1120 \mathrm{rpm}$, the strength is improved at higher WS of $80 \mathrm{~mm} / \mathrm{min}$. This is due to suitable heat generated that helps in good stirring producing minor voids or defect-free joints as indicated by other researchers [25] [26].

Increasing the RS up to $1400 \mathrm{rpm}$ had no meaningful change on the joints strength. This means that the increasing of RS more than $1120 \mathrm{rpm}$ has no effect on the joints strength for different welding speeds. However, the effect of WS is related to the rotational speed. The best strength is found at the higher WS of 80 $\mathrm{mm} / \mathrm{min}$ especially at the high rotational speeds of $1120 \mathrm{rpm}$ and $1400 \mathrm{rpm}$. This is can be attributed to the good flowability of the material which leads to more homogeneity of phases leaving no defects. However, the highest joint performance of $90 \%$ is achieved at $80 \mathrm{~mm} / \mathrm{min}$ where joint's performance is related to the base alloy of lower strength which is AA 5083.

Similar metal joints from previous studies [1] [2] were compared with the present dissimilar FSW joint, based on the joint performance, as shown in Figure 9. The dissimilar joint shows better performance compared to the similar 


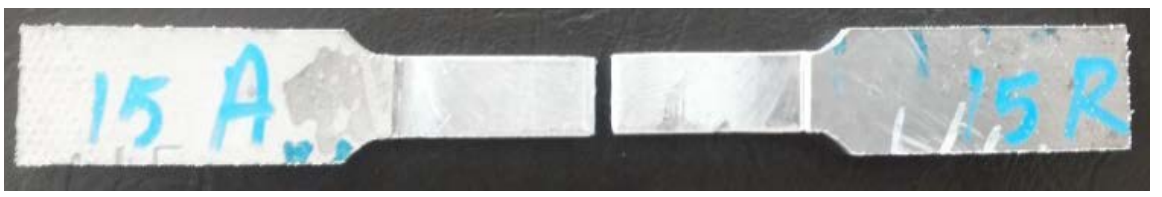

Figure 8. Photograph of tensile specimen fractured at the weld zone.

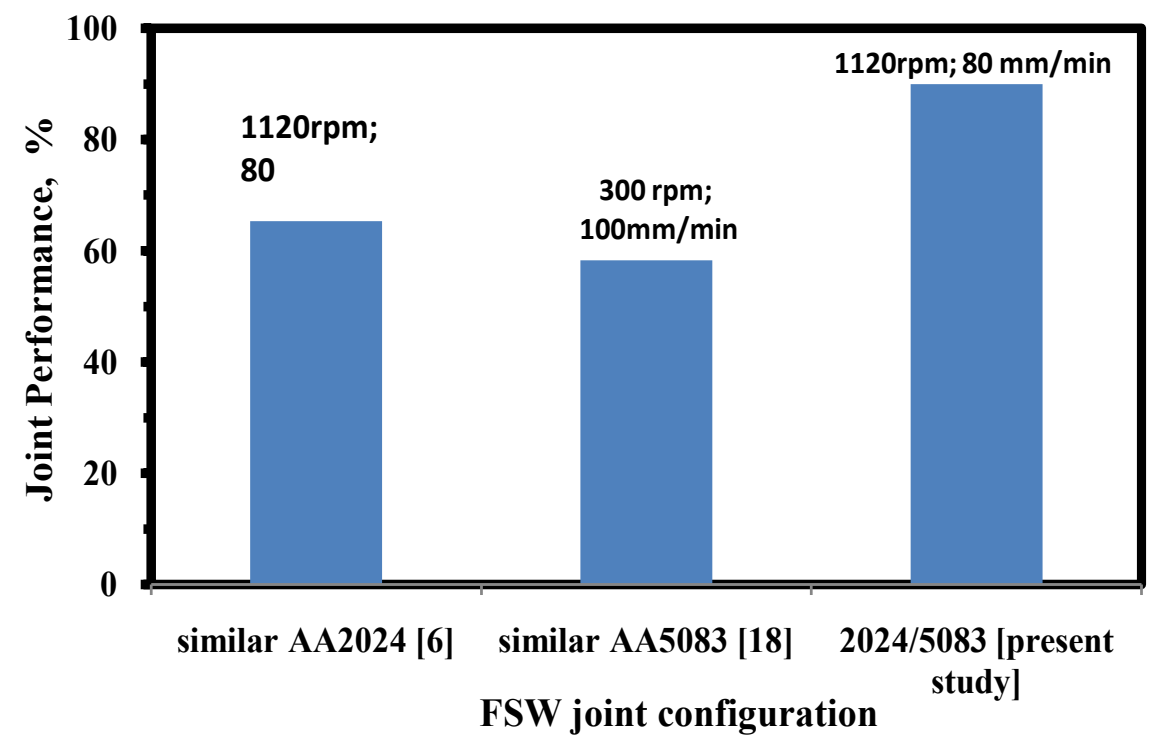

Figure 9. FSW joints performance of similar and dissimilar aluminum alloys.

AA2024 joint as well as the AA5083 joint. Therefore, this indicates that each joint configuration needs its own welding parameters to achieve an appropriate performance. This is in good agreement with previous studies [2] [14] [18] [28].

\subsection{Effect of Tool Geometry}

To investigate the tool geometry effect on the joint strength, WS of $16 \mathrm{~mm} / \mathrm{min}$ is chosen coupled with $900 \mathrm{rpm}$. Three pin designs were used for these experiments, square, prism and stepped. The results of these experiments were plotted in Figure 10. The results show that the square pin produces best strength due to the pulsed action that producing good metal flow, consequently, good stirring. These results are in good agreement with Abd El-Hafez [6] and Kumar et al. [10].

\subsection{Effect of Material Location}

As mentioned at previous studies [11] [12] [15], better strength and a sound joint is achieved when the higher strength alloy is located at AS. To check these results, the effect of the material position is experimentally tested at $900 \mathrm{rpm}$ and $16 \mathrm{~mm} / \mathrm{min}$ using square pin geometry. As shown in Figure 11, the material's position has a noticeable effect on the joint's strength at these parameters when the higher strength alloy (AA2024) is located at AS. However, this result is agree with [15] and [16] whereas disagree with [14]. 


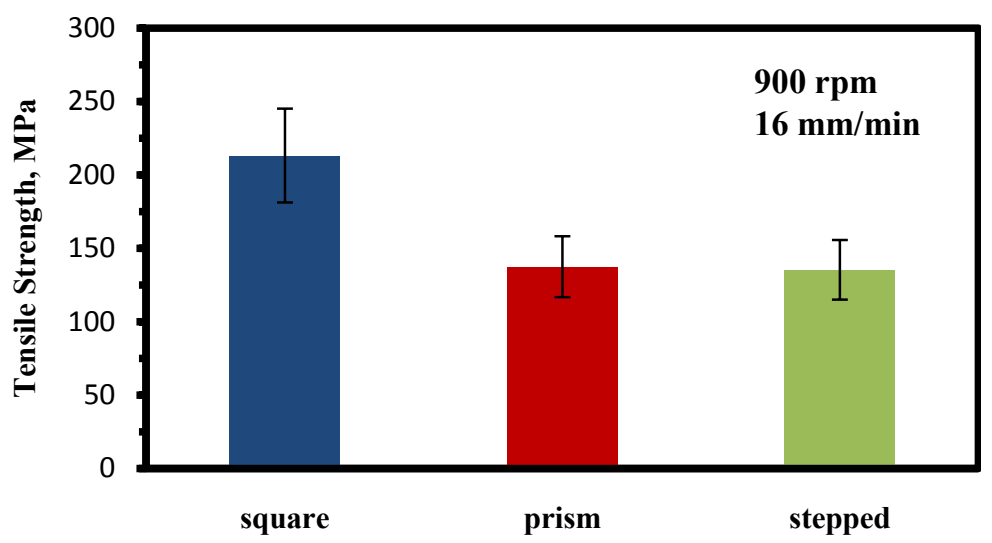

Figure 10. Effect of pin geometry on the tensile strength.

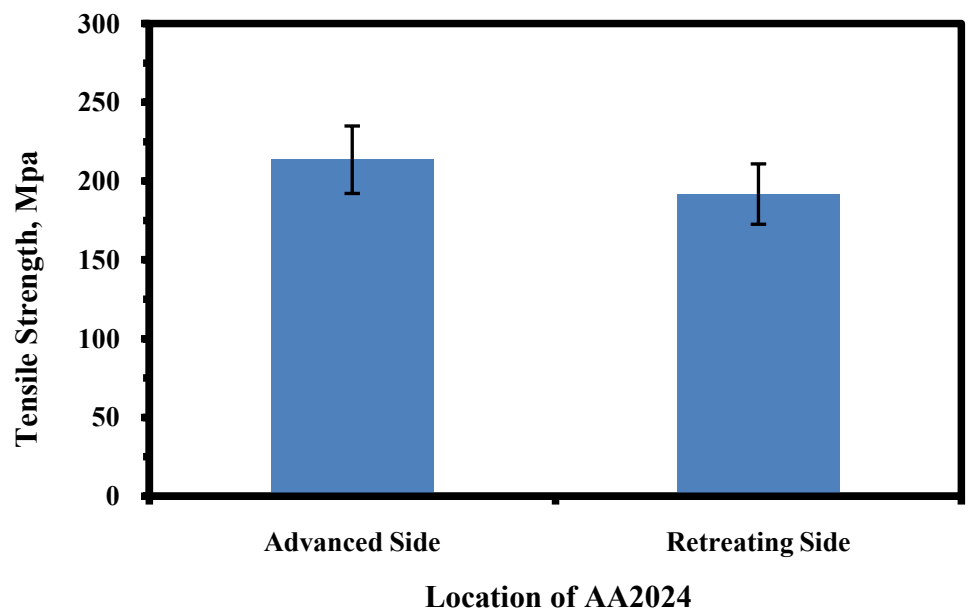

Figure 11. Effect of material location on the joint's strength.

\section{Conclusions}

From the experimental results in this study, it can be concluded that;

1) The welding speed has a significant effect on the strength improvement as well as defect-free joint where the highest speed of $80 \mathrm{~mm} / \mathrm{min}$ achieved good strength improvement at all rotational speeds where the joint performance achieved $90 \%$.

2) The rotational speed has insignificant effect on the joint's strength, when at a speed higher than $1120 \mathrm{rpm}$. The combination of highest speeds of $1120 \mathrm{rpm}$ as well as $1400 \mathrm{rpm}$ and $80 \mathrm{~mm} / \mathrm{min}$ achieved best strength due to the suitable generated heat.

3) Square pin profile produces higher strength joints compared to prism and stepped profiles due to the four pulses per revolution.

4) The material location, where the harder alloy of 2024 at AS, improved the joint strength.

5) The dissimilar 2024/5083 FS-joint has outperformed similar FS-joints AA2024 and AA5083 by about $30 \%$. 


\section{References}

[1] Mishra, R.S. and Ma, Z.Y. (2005) Friction Stir Welding and Processing. Materials Science and Engineering. R: Reports, 50, 1-78. https://doi.org/10.1016/j.mser.2005.07.001

[2] Givi, M.P.A. (2014) Advances in Friction-Stir Welding and Processing. Woodhead Publishing, UK.

[3] Wiechec, M., et al. (2017) Analysis of High-Power Diode Laser Heating Effects on HY-80 Steel for Laser Assisted Friction Stir Welding Applications. World Journal of Engineering and Technology, 5, 97-112. https://doi.org/10.4236/wjet.2017.51009

[4] Abd El-Hafez, H., Abd El-Nasser, G. and El-Baghdady, A. (2007) Effect of the Friction Stir Welding Parameters on the Mechanical Properties of Al 5083 Joint. Proceedings of the $9^{\text {th }}$ International Conference of Al-Azhar Engineering, Egypt.

[5] El-Domiaty, A. and El-Hafez, H.A. (2007) An Energy Model for Friction Stir Welding. Proceedings of the Materials Science \& Technology Conference and Exhibition MS\&T07, Detroit, Michigan, 16-20 September 2007, 435-447.

[6] Abd El-Hafez, H. (2011) Mechanical Properties and Welding Power of Friction Stirred AA2024-T35 Joints. Journal of Materials Engineering and Performance, 20, 839-845. https://doi.org/10.1007/s11665-010-9709-y

[7] Liu, H. Hu, Y., Peng, Y., Dou, C. and Wang, Z. (2016) The Effect of Interface Defect on Mechanical Properties and Its Formation Mechanism in Friction Stir Lap Welded Joints of Aluminum Alloys. Journal of Materials Processing Technology, 238, 244-254. https://doi.org/10.1016/j.jmatprotec.2016.06.029

[8] Mishra, R.S., De, P.S. and Kumar, N. (2014) Friction Stir Processing. In: Friction Stir Welding and Processing, Springer, Berlin, 259-296.

https://doi.org/10.1007/978-3-319-07043-8_9

[9] Sadeesh, P., et al. (2014) Studies on Friction Stir Welding of AA 2024 and AA 6061 Dissimilar Metals. Procedia Engineering, 75, 145-149. https://doi.org/10.1016/j.proeng.2013.11.031

[10] Kumar, N., Monga, I. and Kumar, M. (2015) An Experimental Investigation to Find Out the Effect of Different Pin Profile Tools on AA 6061 T6 and AA 2014 T4 with Friction Stir Welding. International Journal for Technological Research in Engineering, 2, 1622-1625.

[11] Dinaharan, K., Kalaiselvan, S.J. and Vijay, Raja, P. (2012) Effect of Material Location and Tool Rotational Speed on Microstructure and Tensile Strength of Dissimilar Friction Stir Welded Aluminum Alloys. Archives of Civil and Mechanical Engineering, 12, 446-454. https://doi.org/10.1016/j.acme.2012.08.002

[12] Cole, E., et al. (2014) Weld Temperature Effects during Friction Stir Welding of Dissimilar Aluminum Alloys 6061-T6 and 7075-T6. The International Journal of Advanced Manufacturing Technology, 71, 643-652. https://doi.org/10.1007/s00170-013-5485-9

[13] Sundaram, N. and Murugan, N. (2010) Tensile Behavior of Dissimilar Friction Stir Welded Joints of Aluminium Alloys. Materials and Design, 31, 4184-4193. https://doi.org/10.1016/j.matdes.2010.04.035

[14] Khodir, S.A. and Shibayanagi, T. (2008) Friction Stir Welding of Dissimilar AA2024 and AA7075 Aluminum Alloys. Materials Science and Engineering B, 148, 82-87. https://doi.org/10.1016/j.mseb.2007.09.024

[15] Jata, K.V., Mahoney, M.W., Mishra, R.S. and Semiatin, S.L. (2001) Friction Stir Welding and Processing. TMS, Warrendale, PA. 
[16] Xue, P., Ni, D.R., Wang, D., Xiao, B.L. and Ma, Z.Y. (2011) Effect of Friction Stir Welding Parameters on the Microstructure and Mechanical Properties of the Dissimilar Al-Cu Joints. Materials Science and Engineering, A, 528, 4683-4689. https://doi.org/10.1016/j.msea.2011.02.067

[17] Jonckheere, C., de Meester, B., Denquin, A. and Simar, A. (2012) Dissimilar Friction Stir Welding of 2014 to 6061 Aluminum Alloys. Advanced Materials Research, 409, 269-274.

[18] Ahmed, M.M.Z., Ataya, S., El-Sayed Seleman, M.M., Ammar, H.R. and Essam, A. (2017) Friction Stir Welding of Similar and Dissimilar AA7075 and AA5083. Journal of Materials Processing Technology, 242, 77-91. https://doi.org/10.1016/j.jmatprotec.2016.11.024

[19] Leitão, C., Louro, R. and Rodrigues, D.M. (2012) Analysis of High Temperature Plastic Behaviour and Its Relation with Weldability in Friction Stir Welding for Aluminium Alloys AA5083-H111 and AA6082-T6. Materials \& Design, 37, 402-409. https://doi.org/10.1016/j.matdes.2012.01.031

[20] El-Sayed, M.M., Shash, A.Y., Mahmoud, T.S. and Rabbou, M.A. (2018) Effect of Friction Stir Welding Parameters on the Peak Temperature and the Mechanical Properties of Aluminum Alloy 5083-O. In: Öchsner, A. and Altenbach, H., Eds., Improved Performance of Materials, Advanced Structured Materials, Vol. 72, Springer, Cham.

[21] Mohammadtaheri, M.A. (2012) New Metallographic Technique for Revealing Grain Boundaries in Aluminum Alloys. Metallography, Microstructure, and Analysis, 1, 224-226. https://doi.org/10.1007/s13632-012-0033-9

[22] Yoon, S.O., et al. (2012) Friction Stir Butt Welding of A5052-O Aluminum Alloy Plates. Transactions of Nonferrous Metals Society of China, 22, s619-s623. https://doi.org/10.1016/S1003-6326(12)61774-9

[23] Saeidi, M., Manafi, B., Besharati Givi, M.K. and Faraji, G. (2016) Mathematical Modeling and Optimization of Friction Stir Welding Process Parameters in AA5083 and AA7075 Aluminum Alloy Joints. Proceedings of the Institution of Mechanical Engineers, Part B: Journal of Engineering Manufacture, 230, 1284-1294. https://doi.org/10.1177/0954405415573697

[24] Lertora, E. and Gambaro, C. (2010) AA8090 Al-Li Alloy FSW Parameters to Minimize Defects and Increase Fatigue Life. International Journal of Material Forming, 3, 1003-1006. https://doi.org/10.1007/s12289-010-0939-1

[25] Akbari, M., Aliha, M.R.M., Keshavarz, S.M.E. and Bonyadi, A. (2016) Effect of Tool Parameters on Mechanical Properties, Temperature, and Force Generation during FSW. Proceedings of the Institution of Mechanical Engineers, Part L: Journal of Materials. Design and Applications. https://doi.org/10.1177/1464420716681591

[26] Saravanan, V., Rajakumar, S., Banerjee, N. and Amuthakkannan, R. (2016) Effect of Shoulder Diameter to Pin Diameter Ratio on Microstructure and Mechanical Properties of Dissimilar Friction Stir Welded AA2024-T6 and AA7075-T6 Aluminum Alloy Joints. The International Journal of Advanced Manufacturing Technology, 87, 3637-3645. https://doi.org/10.1007/s00170-016-8695-0

[27] Salloomi, K.N., Shammari, A.Z.M. and Ahmed, H.S. (2016) Evaluation of FSW Process Parameters of Dissimilar Aluminium Alloys. Innovative Systems Design and Engineering, 7, 55-69.

[28] Bahemmat, P., Haghpanahi, M., Givi, M.K.B. and Seighalani, K.R. (2012) Study on Dissimilar Friction Stir Butt Welding of AA7075-O and AA2024-T4 Considering the Manufacturing Limitation. The International Journal of Advanced Manufacturing Technology, 59, 939-953. https://doi.org/10.1007/s00170-011-3547-4 